The lock-in effect and the greening of automotive cooling systems in the European Union

Peer-reviewed author version

Bjornavold, Amalie \& VAN PASSEL, Steven (2017) The lock-in effect and the greening of automotive cooling systems in the European Union. In: JOURNAL OF ENVIRONMENTAL MANAGEMENT, 203, p. 1199-1207.

DOI: 10.1016/j.jenvman.2017.06.010

Handle: http://hdl.handle.net/1942/26285 


\title{
The lock-in effect and the greening of automotive cooling systems in the European Union
}

\author{
Amalie Bjørnåvold ${ }^{\mathrm{a}^{*}}$, Steven Van Passel ${ }^{\mathrm{ab}}$ \\ ${ }^{a}$ Faculty of Applied Economics, Department of Engineering Management, University of Antwerp, \\ Prinsstraat 13, 2000 Antwerp, Belgium \\ ${ }^{b}$ Centre for Environmental Sciences, University of Hasselt, Campus Diepenbeek, Agoralaan D, 3590 \\ Diepenbeek, Belgium \\ * Corresponding author: \\ Amalie Bjørnåvold \\ Prinsstraat 13 \\ 2000 Antwerp, Belgium \\ Tel: +32 489759795 \\ E-mail: Amalie.Bjornavold@uantwerpen.be
}

Acknowledgement This work was supported by resources available to the Department of Engineering Management at the Faculty of Applied Economics of the University of Antwerp in Belgium. The paper benefited from discussions at the $11^{\text {th }}$ Conference on Sustainable Development of Energy, Water and Environment Systems (SDEWES), held in Lisbon, Portugal in September 2016. The authors would particularly like to thank the editor and three anonymous referees for providing helpful and constructive comments on earlier versions of the manuscript. 


\title{
HIGHLIGHTS
}

- To reduce fluorinated greenhouse gas emissions from automotive cooling systems, the European Directive 2006/40/EC introduced a gradual ban on these gases as of 2017.

- The market for automotive cooling systems has been 'locked-in', to the advantage of synthetic chemical R-1234yf as opposed to natural solution $\mathrm{CO}_{2}$.

- A generic conceptual model of lock-in and path dependence demonstrates how regulation has reinforced a patented monopoly to 'pick winners'.

- To encourage a sustainable energy transition, policy should focus more on the diversification of technologies, as it is impossible to predict what the most sustainable outcome will be.

\begin{abstract}
As of 2017, the sale and use of the refrigerants most commonly used in automotive cooling systems - hydrofluorocarbons - are entirely banned in all new vehicles placed on the market in the European Union. These refrigerants have been recognised as potent greenhouse gases and, therefore, direct contributors to climate change. It is within this regulation-driven market that the technologies for a sustainable solution have been developed. However, this paper argues that the market for automotive cooling systems has been 'locked-in', which means that competing technologies, operating under dynamic increasing returns, will allow for one potentially inferior technology - to dominate the market. Whilst such a situation is not uncommon, this paper discusses the way that regulation has reinforced a patented monopoly in 'picking winners': to the advantage of a synthetic chemical, R-1234yf, as opposed to the natural solution, which is $\mathrm{CO}_{2}$. By developing a generic conceptual framework of path dependence and lock-in, the presented evidence seeks to show how a snowballing effect has led to the intensification of differences in market share. We also argue that the automotive industry is potentially promoting short-term fixes, rather than long-term, sustainable and economically viable solutions.
\end{abstract}

\section{KEYWORDS}

Mobile air conditioning; automotive cooling; path dependence; lock-in; climate change 


\section{INTRODUCTION}

As we approach the $30^{\text {th }}$ anniversary of the 1989 Montreal Protocol and its successful ban on the use of chlorofluorocarbons (CFCs) - the refrigerants blamed for depleting the ozone layer the gases that were chosen to replace CFCs have, regrettably, been identified as significant contributors to climate change. Hydrofluorocarbons (HFCs), the synthetic refrigerants developed in the 1990s as ozone-friendly alternatives to CFCs, eventually emerged as potent greenhouse gases (GHGs), with thousands of times greater greenhouse potential than $\mathrm{CO}_{2}$. HFCs are the cooling agents that are most commonly used in MAC systems and, with a rapidly expanding market for cooling worldwide, the EU MAC Directive 2006/40/EC, has banned the use of all cooling agents in new passenger vehicles with a global warming potential (GWP) above 150 across the European Union (EU) as of 2017.

The EU MAC Directive is deemed 'technology-neutral'. This means that any substitute to HFC-134a - the refrigerant to be banned (whose GWP is 1430) - is accepted as long as the refrigerant has a GWP below 150. The MAC Directive gave producers five years to develop alternatives to the climate-damaging predecessor from the Directive's implementation in 2006, and through extensive research and testing by manufacturers and suppliers it eventually became clear that the synthetic refrigerant $\mathrm{R}-1234 \mathrm{yf}$ and natural option of $\mathrm{CO}_{2}$ were the major contenders. The EU does not currently mandate the use of either, as long as the aforementioned guidelines are followed (European Commission, 2014).

Although the market for automotive cooling systems in the EU has largely been driven by regulation in recent decades, research continues to remain focused on its technological development, often disregarding the socio-economic conditions driving (or limiting) their development or deployment. This paper seeks to address this gap, and argues that the regulatory framework of the EU has reinforced a patented monopoly held by the producers of $\mathrm{R}-1234 \mathrm{yf}$ - one of the two major contenders. At the time of writing, R-1234yf is widely known as the dominant replacement for HFC-134a MAC systems. It is already used in 18 million vehicles worldwide and all car manufacturers are shifting to R-1234yf, with the exception of Audi and Daimler, which plan to offer $\mathrm{CO}_{2}$ systems as an option in some vehicles in 2017. In order to illustrate the way in which a patented monopoly has been reinforced through a regulatory framework, the objective of this paper is to highlight how the market for MAC systems has been 'locked-in'; this means that when two technologies are in competition with one another, operating under dynamic increasing returns, one (potentially inferior) technology, with a first-mover advantage, will eventually dominate the market.

\subsection{Literature review: path dependence and lock-in revisited}

The concepts of path dependence and lock-in are rooted in evolutionary approaches to understanding technological change. The concepts are broadly used to explain how technologies develop and endure, or why they simply disappear (Cairns, 2014). Central to these approaches is that certain 'choices' (although not necessarily conscious ones) lead to the way in which technologies and systems are designed. Different paths can be taken, which can lead to entirely different technological solutions and products entering the market (Foxon, 2011). Path dependence specifically, as (Margolis, 2009, p. 166) put it, "is a condition in which economic outcomes exhibit inertia." As such, theories of path dependence argue that this evolutionary process of technological development can sometimes get stuck, temporarily and 
sometimes even permanently (North, 1990). Given that technological development in this sense is historically contingent, and not necessarily governed by optimality, a technology can base itself on inferior designs (Marechal, 2009). This concept of path dependence, then, seeks to explain why sub-optimal solutions can sometimes prevail in the market.

David (1985) and Arthur (1989) are considered the pioneers behind technological lock-in, a concept used to understand the technological outcome of path dependence when markets are subject to inertia. The concept especially draws attention to the historically contingent nature of economic change (Marechal, 2007). The idea of lock-in broadly sees that, in the event of two competing technologies being adopted in succession of one another, the market will tend to avoid experimentation, despite other alternatives potentially being superior or more efficient. Scholars of neoclassical economics argue that market processes would allow for a more efficient technology to be taken up by the market, given that manufacturers and users should automatically seek out the most efficient alternative. However, in a world of uncertainty and bounded rationality, this does not necessarily hold with regard to the fast-changing nature of technological change. As such, technologies cannot be considered as isolated mechanisms, but instead belonging to technological systems that include natural, social and institutional elements (Unruh, 2000). Once historical conditions and the interrelation of characteristics have led to the emergence of such a system, their many components lead to the stabilisation and inertia of the system. Solving environmental or social issues through regulatory frameworks in an effective way requires a broader integration of social and natural sciences (Virapongse et al., 2016).

Specifically, through a series of self-reinforcing mechanisms of increasing returns (implying that the more a technology is adopted, the higher the likelihood that even more of the technology will be adopted), there are four classes that can lead to the first technology (out of two) dominating the market; these are (i) scale economies, (ii) learning effects, (iii) adaptive expectations and (iv) network effects (Arthur, 1989). From this, we can draw two central ideas from lock-in. The first is that technological systems can become deeply embedded into inert, durable, potentially sub-optimal and inferior patterns and designs. The second is that these systems are deeply entrenched in complex, interdependent technological and socio-economic systems that can be difficult to escape from. Thus, research into locked-in systems requires taking system-wide policy approaches into account in order to understand their full effect (Perkins, 2003). Understanding the principal causes of this inertia is crucial for enforcing system change (Marechal and Lazaric, 2010). As Carrillo-Hermosilla (2006, p. 718) put it: "early superiority is no guarantee of long-term suitability."

\subsubsection{Self-reinforcing mechanisms}

When two technologies compete for the same market, a snowballing effect can lead to the intensification of minor differences in market share (Arthur, 1989). Choices, or decisionmaking processes, will then exhibit self-reinforcing mechanisms and feedback effects, where inferior and potentially inefficient technologies can become locked in due to chance events. Thus, when increasing returns or feedback effects are present, designs that are inferior can be locked in to the market through a historically path-dependent process in which "circumstantial events determine the winning alternative" (Carrillo-Hermosilla, 2006, p. 718). 


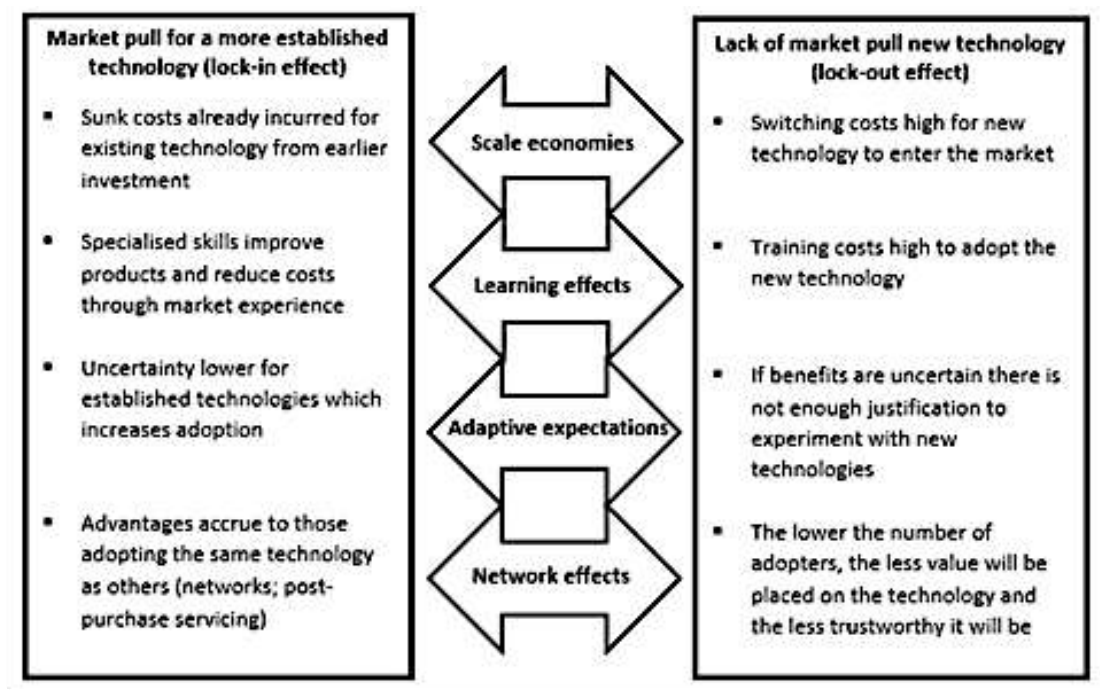

Figure 1. Self-reinforcing mechanisms leading to the lock-in or lock-out of competing technologies

Arthur referred to scale economies as one of four major issues that potentially lead to the lockin of one new technology over another. Although new technologies are initially costly, these costs will decrease the more of the technology is produced (Arthur, 1989). However, significant barriers to entry exist from upfront investment costs, given that immediate cost savings cannot always be guaranteed. Furthermore, the fixed costs previously used to set up and place the dominant technology on the market (sunk costs) exist for technologies already in use, including early investments, which means that the incentives to invest or choose a new technology or alternative are reduced. This adds to the effect of scale economies, whereby cost advantages accrue to the producer that first entered the market. A superior alternative might not be chosen if the expected costs to switching to an alternative outweigh the efficiency gains of facilitating such a transition, which in turn engenders a barrier to adoption and entry (Woerdman, 2015).

Knowledge and experience accumulated over time generally lead to higher returns if you continue along the same production path as before (Kuokkanen et al., 2017). Thus, learning effects usually improve the quality of technologies, while reducing costs, which will in turn intensify the benefits of adopting one technology over another. This means that when two relatively young technologies are competing for the same market, the one that is initially leading in the market share will push it further all along the learning curve; this is because technicians and users will already have acquired skills to take it into use, which will make it more attractive to future adopters (Cowan, 1996). In this sense, learning is path-dependent and the early success of lowering running costs contributes to the condition of lock-in (Woerdman, 2015).

An important indicator of lock-in mechanisms is the notion of adaptive expectations, and more generally, the effect that uncertainty plays on the expected uptake of technologies. Broadly speaking, the theory sees that adoption will increase as uncertainty decreases. This can be attributed to manufacturers or users that consider it too costly to experiment with alternative technologies, given that their expected benefits are not well known, and if some are recognised, they do not provide a decent enough justification for experimentation (Brekke, 2003). This 
means that the increased prevalence of a technology on the market in itself enhances beliefs of future prevalence on the market. In this sense, the expectation held by consumers and endusers that a product will hold a large share of the market redirects demand and induces producers to place significant proportions of a product on the market.

The fourth and final aspect present in locked-in markets is the advantages that benefit those adopting the same technologies as others: network effects (Katz and Shapiro, 1985). Network economies come to the fore given significant interdependencies between systems and users of technologies (Unruh, 2000). As Foxon (2002, p. 4) explained, network effects emerge from systemic interrelations between "technologies, infrastructures, interdependent industries and users. These externalities reinforce the dominance of the system due to both physical and informational networks growing in value to users as they become larger and more interconnected." The more adopters exist in these technological networks, the higher the value users will derive and gain from taking part in them (Barnes et al., 2004).

\subsubsection{Conditions for escaping lock-in}

The lock-in and path dependence literature has thoroughly and consistently studied how these situations come about, but has devoted much less attention to what to actually do to escape it. This is problematic because the lock-in of a technology can manifest significant negative externalities. As seen by Cairns (2014), this effect is frequently noted as entrapment (Walker, 2000), or entrenchment (Collingridge, 1980). The lock-in of technologies has displayed significantly damaging effects on the environment and our health, which has led to an increasing number of scholars studying the link between technological lock-in and ecological change, especially with regard to pollution and the fossil fuel energy distribution system, widely referred to as 'carbon lock-in' (Unruh, 2000); and also within the nuclear industry (Cowan, 1990), end-of-pipe solutions (Kline, 2001), and pest control strategies (Cowan and Gunby, 1996). As seen through the Collingridge dilemma and the notion of societal control of technological development, in the early stages when a technology's applications are relatively simple to reverse, its impacts and effects are uncertain and unpredictable, but when these outcomes and effects are actually known, control and change of the technology is often difficult and even impossible due to the extent of its establishment in the economy. As Collingridge (1980, p. 11) explained:

"When change is easy, the need for it cannot be foreseen; when the need for change is apparent, change has become expensive, difficult, and time-consuming."

Collingridge suggests that the only way around this is to improve anticipative and forecasting tools. One way to avoid this situation is to ensure that technological diversity, or flexibility, is maintained. However, as Huber (2004, p. 295) argued, "lock-in is unavoidable, depending on the stage of structuration and diffusion. But there should always remain certain degrees of freedom." Therefore, it is necessary to distinguish the level of lock-in of a specific technology (Shackley and Green, 2007). It is the depth of the lock-in that can cause issues; the more the flexibility is reduced and 'error cost' increased, the more serious the problems will be, all of which are attributable to the reversibility of the technology.

Furthermore, it is important to highlight the importance of governments or central authorities in internalising externalities, in the sense that switching costs can be reversible, through 
incentives or taxes to encourage adoption of the alternative technology; this suggests that there is room for intervention when it comes to lock-in (van den Bergh et al., 2006). Moreover, encouraging flexibility - that is, incentivising the development of several alternatives - is crucial to responding to the lock-in (Kline, 2001). However, in order for this to occur, authorities must be willing to make these changes and switch from one technology to another in the first place. Unfortunately, breaking out of lock-in is most commonly considered to be achieved through 'external shock', exemplified through the action taken to ban CFCs after the depletion of the ozone layer became common knowledge (Unruh, 2002). Of course, there is no plausible way for policymakers to apply an algorithm that identifies ex ante with certainty which technologies are superior. However, what is sought is that in a climate of bounded rationality and imperfect markets, policymakers can seek vigilance with precautionary tools, rather than a predictive capacity in the face of competing technologies.

\subsection{Research objectives and aims}

The remainder of this paper is divided into four main sections, with final implications, seeking to encourage potential for improved environmental conditions through the diffusion of clean technologies that already exist in the market for automotive cooling systems in the EU. The following section discusses the methods and materials and then presents the case study. The case study is then placed within the conceptual framework of path dependence and lock-in by providing a detailed analysis of how relatively minor events have created a snowballing effect that has led to the synthetic alternative dominating the market for mobile air conditioning. We then discuss how these examples demonstrate how a lock-in effect is displayed in the automotive industry. The paper concludes with policy recommendations, which can have significant implications for policymakers shaping the energy agenda and instigating technological innovation in the mobile air conditioning market.

\section{MATERIALS AND METHODS}

The research approach chosen for the study was a qualitative one, given that it characteristically enables an "exploratory, fluid, flexible, data-driven and context-sensitive analysis" (Mason, 2002, p. 24). The paper in question is based on available literature on the scientific developments of $\mathrm{CO}_{2}$ and R-1234yf systems, as well as legislative documents, at the European level, in order to construct a narrative of the market for automotive cooling systems in the EU in a comparative study of aggregated criteria. In particular, we have analysed these technologies with regard to wider socio-economic implications, described in relation to the socio-technical processes inflicting changes in the development of R-1234yf and $\mathrm{CO}_{2}$ and their subsequent market deployment, or indeed the lack thereof. These findings have then been applied to the conceptual framework described above of path dependence and lock-in. This has been done in order to understand the processes at play and to inspire further policy emphasis on the interplay of existing cause-and-effect chains of technological transition, regulatory change and market interests, in a complex chain of events where systems can be deeply entrenched in complex, interdependent technological and socio-economic systems. 


\section{RESULTS AND DISCUSSION}

We argue that the technological development that has taken shape in the mobile air conditioning (MAC) market in the past decade within the EU has emerged as an obstacle to the deployment of the 'best' or 'greenest' (most sustainable) technology. This development is attributable to the fact that it is the market, not the laboratory, that determines what the socalled best technology will be (Brand, 2005). In the case of mobile air conditioning, however, it can be argued that this market has also taken shape when producers and manufacturers have overestimated demand for it (Parkhurst and Parnaby, 2008). At the beginning of the 1990s, air conditioning systems were a rare luxury in the European automotive market. For instance, in Germany, in 1994 only 19 per cent of vehicles were fitted with MAC systems. By 2002, this figure had jumped to 87 per cent (Gilbert and Perl, 2010). Currently, over 95 per cent of the 13 million vehicles sold in Europe each year contain MAC systems (DUH, 2012). These changes have taken place in Southern and Northern Europe alike, where, at least in the latter, there was no particular consumer interest in owning an air-conditioned car (Wilhite, 2009). Thus, MAC systems have not exactly entered the European automobile market because of a technical solution resolving an urgent demand for comfort, but rather through what has been referred to as a 'conditioning of comfort' (Shove 2008). Additionally, not only did manufacturers and suppliers perhaps over-estimate demand for air conditioning, but the environmental costs to this producer-driven demand have also been substantial (Parkhurst and Parnaby, 2008), while consumers' environmental concern and awareness have increased simultaneously (Nishijima, 2016).

The world is warming, incomes are rising and, despite this potential over-estimation of demand, so are comfort standards. It has been estimated that world consumption of energy for cooling will increase tenfold by 2050 (Isaac and van Vuuren, 2009), with the demand for cooling expected to surpass the demand for heating by 2060 (European Commission, 2016a). It has been estimated that refrigerants accumulating in the atmosphere between now and 2050 (and notably HFCs) will contribute 27 per cent of the increased warming triggered by anthropogenic carbon dioxide emissions (Velders et al., 2009). Whereas HFCs only account for approximately 2 per cent of the EU's overall GHGs, HFC emissions have tripled since 1990 and more than doubled since 1995; this is in contrast to all other GHGs, which have been reduced significantly (European Environment Agency, 2015) and is closely related to the rising use of refrigeration systems. MAC systems on their own increase carbon emissions and other noxious emissions that represent 10 per cent of car emissions, while also increasing the vehicles' fuel consumption by up to 2 litres per $100 \mathrm{~km}$; MAC emissions represent approximately 40 per cent of current global HFC emissions (DUH, 2012). As mentioned above, in an attempt to face this issue, the EU has banned the use of HFCs in automotive cooling systems as of 2017 and all other refrigerants with a higher GWP than 150. As shown in Table 1 below, several changes to refrigerants used have occurred in recent decades. 


\begin{tabular}{lllll}
\hline Refrigerant & $\begin{array}{l}\text { Ozone } \\
\text { depleting? }\end{array}$ & Atmospheric lifetime & $\begin{array}{l}\text { Global } \\
\text { Warming } \\
\text { Potential }\end{array}$ & Years used \\
\hline CFC-12 & Yes & 100 years & 10,900 & 1920 s-1990s \\
\hline HFC-134a & No & 13.4 years & 1,430 & 1990 s-2010s \\
\hline $\mathrm{R}-1234 y f$ & No & 11 days & 4 & 2010 s-present \\
\hline $\mathrm{CO}_{2}$ & No & Naturally occurring & 1 & 2010 s-present \\
\hline
\end{tabular}

Table 1. Overview of refrigerants used in MAC and eventually banned in the past century

Thanks to the 1989 Montreal Protocol phase-out of CFC-12, vehicle manufacturers worldwide transitioned to the use of HFC-134a. As a result of regulations in Japan, Europe, and North America, all passenger vehicle manufacturers are currently shifting to R-1234yf, with the exception of Daimler and the Volkswagen Group, which will be rolling out the use of $\mathrm{CO}_{2}$ systems as an option on some vehicles in 2017 (UNEP, 2016). Organisational pressures to improve environmental management systems are not only attributable to regulatory bodies such as the Montreal Protocol, but also increased public awareness, media exposure on environmental issues, as well as organisations' willingness to improve efficiency through the reduction of environmental costs (Phan and Baird, 2015).

R-1234yf is certainly more environmentally friendly than its predecessors, given that it decomposes faster in the atmosphere (11 days compared to 13.4 years for HFC-134a and 100 years for CFC-12) and has a very low GWP of 4 . As its manufacturers have pointed out; using R-1234yf globally would be the equivalent to removing over 30 million cars from the road permanently (Honeywell, 2013). Additionally, it is very simple to retrofit in existing systems due to its similarity to the former HFC-134. Further, as Ansari et al. (2013, p. 143) noted, "even though the values of the performance parameters for R-1234yf are smaller than that of HFC-134a, the difference is small, so is therefore a good alternative to HFC-134a because of its environmentally friendly properties." However, it is becoming increasingly clear that, in terms of ozone depletion and the greenhouse effect, the problem with MAC refrigerants has been solved, but the ecosystem may be facing new challenges. The first measurements of the chemical show that R-1234yf breaks down into a new substance, trifluoroacetic acid (TFA), a stable molecule and strong acid that does not naturally decompose further and could potentially be toxic for certain plants and algae from large-scale usage (Smit et al., 2009; Vollmer et al., 2015). Even though TFA is a common by-product of other HFCs, R-1234yf has been shown to yield over 90 per cent TFA (4-5 times as much as HFC-134a) (Kauffeld, 2012). As Luecken et al. (2010, p. 343) showed, "automobile air conditioning R-1234yf emissions are predicted to produce concentrations of TFA in Eastern U.S. rainfall at least double the values currently observed from all sources, natural and man-made”. Despite this, TFA is currently considered to present an insignificant risk to the environment and ourselves (UNEP, 2016). This is because it has shown to be of very low toxicity (Boutonnet et al., 1999), with peak TFA levels being at $1.26-1.7070 \mu \mathrm{g} / \mathrm{L}$, which is $60-80$ times lower than the accepted safety level (KTH Royal Institute of Technology, 2015; Luecken et al., 2010). Nonetheless, these results are believed to be underestimations because they do not take into account the use of R-1234yf beyond the MAC sector, in addition to its variation in concentration depending on the seasonal precipitation patterns. Thus, the toxicity of TFA and its use in R-1234yf remains an open question (Kajihara et al., 2010; KTH Royal Institute of Technology, 2015). Moreover, it has also been reported that 20 per cent of the gases produced by the combustion of R-1234yf 
consist of the toxic chemical carbonyl fluoride, in addition to hydrogen fluoride, which can be released in a collision and ignite at high temperatures (it is known to ignite at $405^{\circ} \mathrm{C}$ ) and is both toxic and can be fatal in high doses (Feller et al., 2014). This is deemed to be extremely unlikely, however and has despite this paved its way into the industry.

At the same time, $\mathrm{CO}_{2} \mathrm{MAC}$ systems have also been developed to a stage where they have demonstrated their technical feasibility and comparable energy consumption. Although $\mathrm{CO}_{2}$ is the largest contributor to anthropogenic climate change, its use in technical applications is normally considered to be sound given that $\mathrm{CO}_{2}$ used in refrigeration and fire-fighting systems is a waste product that would otherwise have escaped into the atmosphere. Thus, waste $\mathrm{CO}_{2}$ can become part of the solution to climate change, whereas competing chemical alternatives require manufacturing from scratch and accompany the aforementioned environmental uncertainties. This means it is both natural and safe however, at the moment it is also somewhat more expensive and technically demanding given that these systems need to be developed and designed due to higher operating pressures and leakage detection problems. Nonetheless, by recycling this industrial waste product into a natural refrigerant for cooling a car, it can become environmentally benign. Analyses of the emission and life cycle climate performance (LCCP) have shown that $\mathrm{CO}_{2}$ components show significant advantages in terms of greenhouse gas emissions over time against R-134a and R1234yf under nearly all climatic conditions (Cavallini and Zilio, 2007; Hafner and Nekså, 2004). Furthermore, research by SINTEF found that prototype $\mathrm{CO}_{2}$ air-conditioning systems in railway passenger coaches had significantly lower energy demands ( $\sim 52$ per cent less than the R-134a system). In this sense, this example shows that $\mathrm{CO}_{2}$ are more energy-efficient than HFC units (Haukås and Pachai, 2015). Moreover, a further reduction in energy consumption is expected as MAC systems are combined with heat pump modes for the compartment heating for cooler season. Moreover, the leakage detection and operating pressures can be improved through further research and design (Cavallini and Zilio, 2007). Further, as early as 2008, $\mathrm{CO}_{2}$ systems had 30 per cent lower fuel consumption than similar ones using hydrofluorocarbons (Hafner, 2016). A prototype of a $\mathrm{CO}_{2}$ air conditioning system that a heat pump in city buses has also been shown to save up to 50 per cent of fuel for heating, with potential for further improvements (Nekså, 2004).

\subsection{SELF-REINFORCING MECHANISMS: THE LOCK-IN OF THE EUROPEAN AUTOMOTIVE COOLING MARKET}

This section seeks to highlight the way in which the market for MAC in the EU is showing evidence of path dependence and lock-in through the existence of self-reinforcing feedback mechanisms; or, more generally, increasing returns. Given that the technological development and deployment of climate-friendly cooling agents is occurring at a rapid pace, and is largely driven by regulation, it is critical to recognise whether short-term fixes or long-term economically viable and sustainable solutions are being promoted in MAC systems. With R1234yf entering the market as the dominant technology, we argue that, in the development of sustainable technologies in mobile air conditioning, we are seeing tendencies of the "technical fix approach" rather than more preventative approaches of technological diversification, despite the potential environmental effects of R-1234yf remaining inconclusive. 


\subsubsection{Scale economies}

As described above, self-reinforcing mechanisms, or feedback effects, will favour and support the initial and dominant choice, while competitors, and perhaps more efficient alternatives, are left on the sidelines. When referring to scale economies and the lock-in effect, it is important to take into account the significant sunk cost that exists for technologies that are already on the market. This refers to early investments made in production, equipment, training and so on, which reduce incentives for manufacturers to opt for an alternative. In the case of R-1234yf and $\mathrm{CO}_{2}$, a majority of automotive manufacturers already consider the switching costs high enough to transition to R-1234yf, and even higher to take $\mathrm{CO}_{2}$ on board. Informal discussions with industry stakeholders indicate that the present price of R-1234yf in the European market is approximately $\$ 80$ per $\mathrm{kg}$. This is at least five times the price of the predecessor, HFC-134a. On top of that, $\mathrm{CO}_{2} \mathrm{MAC}$ systems are expected to cost between \$50-100 more per system than R-1234yf (DUH, 2012).

At first glance, the ideas of lock-in and scale economies seem to apply well to the case of R1234yf. However, this is not merely a question of costs. R-1234yf was first developed by Honeywell International and DuPont, which has now shifted its flourochemical business to a new company entitled Chemours; and Arkema Chemicals. These multinational companies have not shown much interest in sharing the market for refrigerants with competing technologies: they hold all production patents for the chemical and lobby heavily for the phasing out of the predecessor HFC-134a (which Honeywell and DuPont were the manufacturers of to begin with), and argue for the benefits of R-1234yf over competing, natural alternatives (Wodzisz, 2015). Due to the lack of patentability of natural refrigerants (as they are naturally occurring), natural refrigerants were initially perceived to be less valuable for businesses. Further, R-1234yf has very similar thermophysical properties to HFC-134a and can therefore can be used as a retrofit or 'drop-in replacement' to replace HFC-134a in MAC systems (Navarro-Esbrí et al., 2013). This means that it can be used with only minor equipment changes to existing vehicle AC systems and has led to close to 18 million cars using R-1234yf by the end of 2016 (Seidel et al., 2016). In contrast, $\mathrm{CO}_{2}$ only operates under very high operating pressures - almost 10 times more than R-1234yf - and therefore requires entirely new equipment. For this reason, almost every part of the system, from compressors to heat exchangers, requires redesigning in order to handle these higher pressures (Haukås and Pachai, 2015).

As Unruh (2002) maintains, when climate change and environmental degradation arises from a locked-in technological system, the first solutions that are sought are those that minimise changes to existing systems. Unruh further underlined that the least impactful solution will inevitably be to keep the existing infrastructure, with potential add-ons to those already in place, and leave the overall architecture unchanged. These often focus on intra-system innovations that keep costs to the minimum. As car companies already had to switch after the CFC phase-out in the 1990s, new equipment had to be replaced to start using HFC-134a, and the costs are considered too large to make changes once again.

In the case of R-1234yf and $\mathrm{CO}_{2}$, however, it can be argued that EU regulation, through the MAC Directive, particularly incentivises the use of R-1234yf in the MAC sector on its own, whilst barring market entry for competitors. It was due to safety concerns of the potential flammability (ignition) and toxicity concerns in the event of a collision that the Volkswagen Group and Daimler chose to invest in developing $\mathrm{CO}_{2}$ systems. However, in December 2015, 
Germany was referred to the European Court of Justice as the EU claimed that Daimler did not "make the necessary technical adaptations to ensure full compliance with the MAC Directive" (European Commission, 2015). In continuing to use HFC-134a, Daimler argued that it was simultaneously developing air conditioning systems for its vehicles that can use $\mathrm{CO}_{2}$, given that Germany had given Daimler permission to keep using HFC-134a while developing alternative solutions in 2013. In a compromise reached in October 2015, Daimler agreed to use R-1234yf in the interim while continuing to manufacture systems capable of using $\mathrm{CO}_{2}$. All other carmakers believe R-1234yf to be safe (Haukås and Pachai, 2015). Given the lack of flexibility on behalf of the EU MAC Directive, regulation has reinforced this patented monopoly for refrigerants and led to the lock-in of R-1234yf in automotive cooling systems.

Furthermore, although it has been claimed that R-1234yf makes the transition to new cooling agents easier for the industry, in reality this transition may do the opposite, and the argument of lower switching costs does not hold if the question of long-term refrigerant supply is brought into the question. $\mathrm{CO}_{2}$, as a gas, is released as an industrial waste product directly into the atmosphere: the constraining issue for $\mathrm{CO}_{2} \mathrm{MAC}$ will not be triggered by its availability and would allow for a greater variety of industry players to enter the market due to the refrigerant's lack of patentability. Contrastingly, R-1234yf requires manufacturing from scratch, while at the same time potentially decomposing into environmentally damaging substances. Additionally, the production capacity of R-1234yf is presently incapable of supplying for worldwide demand (Andersen et al., 2013), which means that costs are still high, despite similarities to the former refrigerant.

\subsubsection{Learning effects}

Knowledge and experience accumulated over time generally leads to higher returns if you continue along the same path as before (Kuokkanen et al., 2017). In this sense, learning effects usually improve the quality of technologies, at the same time as reducing costs, which will in turn intensify the benefits of adopting one technology over another. This means that when two relatively young technologies are competing for the same market, the one that is initially leading in market share will push it further all along the learning curve, rendering it even more attractive to future adopters (Cowan and Gunby, 1996). In this sense, learning is pathdependent, and the early success of lowering running costs contributes to the condition of lockin (Woerdman, 2015). Thus, the transition to a low-carbon, high-efficiency economy represents a structural change in the labour market, which is not just about creating new jobs, but also about changing modes of production (Valente et al., 2015). What is needed is a 'topping up' of existing job-related skills in order to avoid disconnects between the demand and supply of skills. It is necessary to forecast future skills and occupational demands so that skilled employees are preconditions for further growth in the environmental protection sector. Stricter environmental management can also reduce the organisational flexibility of a company, given that substantial capital investments and changes in systems and methods of production enterprises are required (Lannelongue et al., 2017).

Mobile air conditioning is a knowledge-intensive industry that requires both training and experience. Furthermore, this is not the first time that vehicles' refrigerants have changed. Given the significant difference between $\mathrm{CO}_{2}$, and with R-1234yf, and the heat exchangers and compressors being the same, it becomes easier to choose the latter as it is so similar to its predecessor, R-134a. Given that supplier industries will have an interest in keeping technologies they already know and have expertise in, this will have an effect on automakers' 
choices in choosing of technologies. In addition, repair and maintenance workers in local garages and car workshops will have an incentive to learn how to repair the dominant refrigeration system. As only a few operators use $\mathrm{CO}_{2} \mathrm{MAC}$ systems, there are not yet any significant incentives to learn how to use unconventional MAC systems.

The number of technicians trained in the different alternative refrigerants as a percentage of the total number of technicians trained to handle replacement technologies for $\mathrm{f}$-gases and HFCs is very low in the EU as a whole ( $0-2.3$ per cent). As was recently been reported by the (European Commission, 2016b) on the "availability of training for service personnel regarding the safe handling of climate-friendly technologies replacing or reducing the use of fluorinated greenhouse gases", the uptake of alternative refrigerants is being held back by the lack of training and familiarity by service personnel and end-users. The European Commission further reports that if the appropriate training is not made available across the continent, the transition to alternative refrigerants may result in higher costs than necessary, with "the lack of trained service providers an important factor for abstaining from a conversion to alternative refrigerants, e.g. to the use of $\mathrm{CO}_{2}$ ” (European Commission, 2016b, p. 9).

Regulation (EU) No 517/2014 on fluorinated greenhouse gases requires technicians to acquire practical and theoretical training on the replacement and reduction of f-gases and alternative solutions, relating to product safety and risk such as flammability and high-pressure equipment. This means that it is currently illegal for employers to hire technicians who carry out installations, product designers, as well as maintenance and end-of-life decommissioning, without adequate risk mitigation training. As the European Commission (2016b) warned, training provided within the $\mathrm{EU}$ is currently insufficient to keep pace with the demand for alternative refrigerants and is slowing down potential market uptake. $\mathrm{CO}_{2}$ can also be used in heat pumps, refrigerators and air conditioners. It is crucial to increase training in equipment use and risk management, given that $\mathrm{CO}_{2}$ requires a specific skill-set due to certain drawbacks (described above) with $\mathrm{CO}_{2}$ MAC systems, such as leak detection issues, which can only be solved with greater $R \& D$ investment (Spletzer, 2016). Specifically, in the case of mobile air conditioning, lock-in is increasingly becoming a problem given that automakers would rather choose the refrigerant that they know mechanics and local garages will know how to use. However, increased training on $\mathrm{CO}_{2}$ refrigeration would be able to change this situation (Spletzer, 2016).

\subsubsection{Adaptive expectations}

Lock-in theory argues that adoption will increase as uncertainty decreases. There are significant uncertainties with regard to the safety of the two competing technologies in MAC systems. Phasing in new refrigerants is likely to take decades. Given the existence of a cyclical pattern of regulatory changes with regard to air conditioning systems, which is directly linked to growing awareness of environmental risk as well as technological development, and uncertainty involved in what the future in regulatory change might be, Unruh (2002) and Cowan and Gunby (1996) argued that it will take a "crisis" to break out of the lock-in. The automotive industry already had to change systems from CFCs to HFCs in the 1990s; this has been followed by the current situation and it will take a lot of convincing before the rest of the industry players will change from R-1234yf to $\mathrm{CO}_{2}$. The uncertainty with regard to changes in regulation and refrigeration may lead to inertia, which makes looking into new alternatives less attractive. 
With regard to the bounded rationality of actors, a point can be made in reference to the difficulty of accessing and processing information needed to make economic decisions - for consumers, to firms, and governments - due to the uncertainty of future events (Foxon, 2011). What is particular in the case of path dependence and lock-in is that decision-makers do not allow for the development or use of a superior alternative; even though they know of its existence, they largely understand its characteristics and consider uncertainties inherent in its existence to be acceptable. There are significant uncertainties with regard to the safety of the two competing technologies in MAC systems. Whilst R-1234yf has been thoroughly tested to ensure its safety, and has met safety regulations, Daimler's tests show that it can ignite when it comes into contact with a hot engine, even though R-134a and $\mathrm{CO}_{2}$ did not (Haukås and Pachai, 2015). As discussed above, research has also shown that it may significantly damage the ecosystem, and potentially users as well. Some tests have shown that R-1234yf is not dangerous, which has pushed manufacturers further into adopting the refrigerant. However, the more tests that show it is safe, the more opportunity R- $1234 \mathrm{yf}$ has to promote its product. The most renowned of these is the SAE report, which legitimises its use and states that it is a safe alternative to R-134a. With Daimler and the Volkswagen Group switching over to $\mathrm{CO}_{2}$ and the rest of the world using R-1234yf, we now have a split in the automotive air conditioning market. Given this high uncertainty, when applying the theory of lock-in, car manufacturers might in this case be undersupplying experimentation into alternative solutions. Thus, as seen above, the industry and policymakers consider the uncertainties inherent to its existence acceptable: a key condition to locked-in technologies.

\subsubsection{Network effects}

Network effects see that when more adopters exist in technological networks, users will derive and gain greater value from taking part in them. As an example, the provision of post-purchase services for durable goods displays the issues inherent in the way certain products provide a utility as a function of the amount of people using them. An example that is relevant to the case of R-1234yf is one illustrated by Katz and Shapiro (1985). They maintained that, in markets for vehicles, sales of foreign models of cars are relatively low compared to those of local cars, or at least not as rapid as with other markets, given that consumers often perceive networks of repair services for different models to be lower and less experienced. What this means is that using a lesser-known refrigerant entails a risk, given that it will be less likely to attain post-purchase services for the consumer.

In addition, product information is also more widely available for better-known brands and there may also be conformity or psychological bandwagon effects. How the EU MAC Directive's regulatory framework allows for network effects to enhance the market dominance of R-1234yf largely relates to lobbying impact. Considerable sums are devoted to lobbying the European Parliament and EU decision makers by the refrigerant sector, and there are significant differences regarding the difference between synthetic and natural alternatives. In 2013, companies producing fluorinated gases (thus R-1234yf) spent almost 24 million euros, compared to the 900,000 euros spent by alternative industries looking for substitutes. Large multinationals, both by themselves and with the help of lobbyists such as European Partners for Energy and the Environment and the European Fluorocarbons Technical Committee, have invested significant time and money in heavy lobbying in the run-up to the implementation of EU Directive 2006/40/EC, and have therefore potentially prevented a leapfrogging or an easier market entry for other efficient and safe alternatives such as $\mathrm{CO}_{2}$ (CEO, 2013). Moreover, the more suppliers sell the product, the more likely it is that others will adopt it as 
well. For instance, R-1234yf is widely available, whereas $\mathrm{CO}_{2}$ is only being adopted gradually. SANDEN, a potential $\mathrm{CO}_{2}$ MAC supplier that develops and supplies $\mathrm{CO}_{2}$ refrigeration in commercial and industrial applications, stated that it has completed $\mathrm{R} \& \mathrm{D}$ activities for $\mathrm{CO}_{2}$ use in mobile air conditioning, but "did not reach commercialization development because of the direction taken by customers to go for R-1234yf" (Andersen et al., 2013). However, buses continue to rely on HFC-134a, with the trend towards hybrid electric buses allowing hermetic or semi-hermetic compressors, which renders the use of R-744 more likely (UNEP, 2016). Furthermore, the fact that Daimler and the Volkswagen Group are rolling out $\mathrm{CO}_{2} \mathrm{MAC}$ units for use will potentially, with the help of policy and incentives, enable other companies to take advantage of them, too.

\section{CONCLUSION}

Understanding technological change through an evolutionary framework of lock-in and path dependency means that the eventual outcome emerges through an uncertain and complex nature of complex interactions and dynamics. What is of concern is when a situation of lock-in occurs when actors and decision-makers do not allow for the development or use of a superior alternative, even though potential risks or costs of the dominant alternative are understood. It is important for policy-makers to abstain from 'picking winners' and to instead look to allow for the creation of conditions in evolutionary processes of technological transitions that can lead to the preferred outcome (Marechal, 2009). In such a way, it is important to take facets of evolutionary economics into account so that policies focusing on technology development and deployment can promote the diversification of technologies and strategies, instead of maintaining static economic efficiency as the main objective (van den Bergh et al., 2006). In order for this to become a reality, it is firstly important that the limits to 'technical fixes' are recognised (Parkhurst and Parnaby, 2008), in the sense that there cannot be a single solution to any problem. Specifically, policy needs to allow for the support of alternative technologies, through training, incentives and subsidies.

This paper has argued that the market for mobile air conditioning in the EU is being locked-in, to the advantage of synthetic option R-1234yf, instead of natural solution $\mathrm{CO}_{2}$. While it is not uncommon for one technology to take over the market to a greater extent than a competitor, what is particular in this case is the degree to which the uncertainty and risks inherent in the dominant solution are still widely accepted, with the degree of freedom of entry of alternatives significantly restricted - reinforced by the regulatory environment in which they are placed and potentially skewed lobbying influences in policy. As research is pointing to more damaging releases of chemicals into the atmosphere, we should be more cautious in committing ourselves (or allowing the automotive industry to commit itself) to the adoption of one technology without allowing alternatives to survive and develop.

Specifically, there was no lead-time to develop alternative solutions for the mobile air conditioning market and, as a result, the MAC Directive reinforced the market position of R$1234 y f$ through an intensification of scale economies, learning effects, adaptive expectations and network effects. Further research and awareness into the issues at stake with regard to the potential lock-in of R-1234yf is crucial in order to ensure that technological diversity is maintained and that alternatives can survive and develop. Regulation needs to take costs and timing into account when determining how changes affect parties; these include administrative, legal and institutional contexts (O'Ryan et al., 2006). The more the flexibility is 
reduced and the extent to which the 'error cost' is increased, the greater the complications will be.

Policymakers worldwide are increasingly responding to rapidly evolving environmental risks. Against this background, we recommend that policy attach greater importance to market power when designing clean technology markets. If emerging markets for clean technology unnecessarily lock in patented technologies - as we argued to be the case for the EU MAC Directive, and effectively granting a monopoly to one firm - the monopolist is likely to reap most of the benefits of green technologies. In addition, as it is in many cases the state that funds the basic research enabling innovation (Mazzucato, 2015), it is important that consumers and taxpayers also reap the fruit of these innovations. To avoid the monopolisation of clean technology markets, policymakers therefore ought to ensure that their transition pathways leave sufficient time for the development of competing technologies and substitutes. As a consequence, we suggest placing a higher emphasis on the competitive benefits of substitutes for clean technologies, which can potentially be highlighted through regulatory impact assessments conducted by the European Commission for instance. While re-election concerns may sway policymakers to phase-out polluting technologies as quickly as possible, moving slowly may sometimes be superior in the long-term to ensure that short-term fixes are not promoted, but rather sustainable and economically viable solutions. 


\section{REFERENCES}

Andersen, S.O., Halberstadt, M.L., Borgford-Parnell, N., 2013. Stratospheric ozone, global warming, and the principle of unintended consequences-An ongoing science and policy success story. J. Air Waste Manage. Assoc. 63, 607-647. doi:10.1080/10962247.2013.791349

Ansari, N.A., Yadav, B., Kumar, J., 2013. Theoretical Exergy Analysis of HFO-1234yf and HFO-1234ze as an Alternative Replacement of HFC-134a in Simple Vapour Compression Refrigeration System. Int. J. Sci. Eng. Res. 4, 137-144.

Arthur, W.B., 1989. Competing technologies, increasing returns, and lock-in by historical events. Econ. J. 99, 116-131. doi:10.1017/CBO9781107415324.004

Barnes, W., Gartland, M., Stack, M., 2004. Old Habits Die Hard: Path Dependency and Behavioral Lock-in. J. Econ. Issues 38, 371-377. doi:10.2307/4228022

Boutonnet, J.C., Bingham, P., Calamari, D., Rooij, C. de, Franklin, J., Kawano, T., Libre, J.-M., McCul-loch, A., Malinverno, G., Odom, J.M., Rusch, G.M., Smythe, K., Sobolev, I., Thompson, R., Tiedje, J.M., 1999. Environmental Risk Assessment of Trifluoroacetic Acid. Hum. Ecol. Risk Assess. An Int. J. 5. doi:10.1080/10807039991289644

Brekke, K.A., 2003. Market-based Lock-in and Environmental Technologies: The Importance of Increasing Returns to Adoption.

Cairns, R.C., 2014. Climate geoengineering: Issues of path-dependence and socio-technical lock-in. Wiley Interdiscip. Rev. Clim. Chang. doi:10.1002/wcc.296

Carrillo-Hermosilla, J., 2006. A policy approach to the environmental impacts of technological lock-in. Ecol. Econ. 58, 717-742. doi:10.1016/j.ecolecon.2005.09.001

Cavallini, A., Zilio, C., 2007. Carbon dioxide as a natural refrigerant. Int. J. Low Carbon Technol. 2, 225-249. doi:https://doi.org/10.1093/ijlct/2.3.225

CEO, 2013. HFC Report.

Collingridge, D., 1980. The Social Control of Technology. Frances Pinter, London.

Cowan, R., 1990. Nuclear Power Reactors: A Study in Technological Lock-in. J. Econ. Hist. 50, 541. doi: $10.1017 /$ S0022050700037153

Cowan, R., Gunby, P., 1996. Sprayed to Death: Path Dependence, Lock-in and Pest Control Strategies. Econ. J. 106, 521-542. doi:10.2307/2235561

David, P.A., 1985. Clio and the Economy of QWERTY. Am. Econ. Rev. 75, 332-337. doi: $10.2104 /$ ha080079

DUH, 2012. Environmentally friendly cooling. Berlin, Germany.

European Commission, 2016a. An EU Strategy on Heating and Cooling, Dynamical systems with applications using MATLAB. doi:10.1017/CBO9781107415324.004

European Commission, 2016b. The availability of training for service personnel regarding the safe handling of climatefriendly technologies replacing or reducing the use of fluorinated greenhouse gases. Brussels.

European Commission, 2016c. Communication from the Commission to the European Parliament, the Council, the European Economic and Social Committee and the Committee of the Regions on an EU Strategy for Heating and Cooling. COM(2016) 51 final.

European Commission, 2015. Commission refers Germany to the Court of Justice of the EU over failure to apply Directive on mobile air conditioning [WWW Document]. Press Release Database. URL http://europa.eu/rapid/press-release_IP-15-6290_en.htm

European Commission, 2014. Refrigerants used in mobile air condition systems (MAC) 
[WWW

Document].

URL

https://ec.europa.eu/growth/sectors/automotive/environment-protection/mobile-airconditioning-systems_en

European Environment Agency, 2015. Production, sales and emissions of fluorinated greenhouse gases (F-gases). Copenhagen, Denmark.

Feller, M., Lux, K., Hohenstein, C., Kornath, A., 2014. Structure and properties of 2,3,3,3tetrafluoropropene (HFO-1234yf). Zeitschrift fur Naturforsch. - Sect. B J. Chem. Sci. 69, 379-387. doi: $10.5560 / Z N B .2014-4017$

Foxon, T.J., 2011. A coevolutionary framework for analysing a transition to a sustainable low carbon economy. Ecol. Econ. 70, 2258-2267. doi:10.1016/j.ecolecon.2011.07.014

Foxon, T.J., 2002. Technological and institutional "lock-in" as a barrier to sustainable innovation, Imperial College Centre for Energy Policy and Technology (ICCEPT). London.

Gilbert, R., Perl, A., 2010. Transport Revolutions: Moving People and Freight without Oil. New Society Publishers, Gabriola Island, British Columbia.

Hafner, A., 2016. Natural refrigerants, a complete solution - Latest technological advancements.

Hafner, A., Nekså, P., 2004. Life Cycle Climate Performance (LCCP) of mobile airconditioning systems with HFC-134a, HFC-152a and R-744, in: MAC Summit. Washington, D.C., p. 13.

Haukås, H., Pachai, A.C., 2015. Nordic Working Papers: Information Sheets on Natural Refrigerants, Nordiske Arbejdspapirer, 2014:908. Copenhagen, Denmark. doi:10.6027/NA2014-908

Honeywell, 2013. Honeywell announces major investments to increase HFO-1234yf production in the United States [WWW Document]. URL https://www.honeywellrefrigerants.com/europe/?press_release=honeywell-announces-major-investments-toincrease-hfo-1234yf-production-in-the-united-states (accessed 12.12.16).

Huber, J., 2004. New technologies and environmental innovation. Edward Elgar, Cheltenham, UK.

Isaac, M., van Vuuren, D.P., 2009. Modeling global residential sector energy demand for heating and air conditioning in the context of climate change. Energy Policy 37, 507-521. doi:10.1016/j.enpol.2008.09.051

Kajihara, H., Inoue, K., Yoshida, K., Nagosa, R., 2010. Estimation of environmental concentrations and deposition fluxes of R-1234-YF and its decomposition products emitted from air conditioning equipment to atmosphere, in: International Symposium on Next-Generation Air Conditioning and Refrigeration Technology. Tokyo.

Katz, M.L., Shapiro, C., 1985. Network Externalities, Competition, and Compatibility. Source Am. Econ. Rev. 75, 424-440. doi:10.1126/science.151.3712.867-a

Kauffeld, M., 2012. Availability of low GWP alternatives to HFCs: Feasibility of an early phaseout of HFCs by 2020. London.

Kline, D., 2001. Positive feedback, lock-in, and environmental policy. Policy Sci. 34, 95-107. doi:10.1023/A:1010357309367

KTH Royal Institute of Technology, 2015. The potential dangers of TFA [WWW Document]. URL https://www.kth.se/en/itm/inst/energiteknik/forskning/ett/projekt/koldmediermed-lag-gwp/low-gwp-news/potentiella-faror-med-trifluorattiksyra-tfa-1.602615 (accessed 2.1.17).

Kuokkanen, A., Mikkila, M., Kuisma, M., Kahiluoto, H., Linnanen, L., 2017. The need for policy to address the food system lock-in: A case study of the Finnish context. J. Clean. 
Prod. 140, 933-944. doi:10.1016/j.jclepro.2016.06.171

Lannelongue, G., Gonzalez-Benito, J., Quiroz, I., 2017. Environmental management and labour productivity: The moderating role of capital intensity. J. Environ. Manage. 190, 158-169. doi:10.1016/j.jenvman.2016.11.051

Luecken, D.J., Waterland, R.L., Papasavva, S., Taddonio, K.N., Hutzell, W.T., Rugh, J.P., Andersen, S.O., 2010. Ozone and TFA impacts in North America from degradation of 2,3,3,3-tetrafluoropropene (HF0-1234yf), A potential greenhouse gas replacement. Environ. Sci. Technol. 44, 343-348. doi:10.1021/es902481f

Marechal, K., 2009. An Evolutionary Perspective on the Economics of Energy Consumption: The Crucial Role of Habits. J. Econ. Issues 43, 69-88.

Maréchal, K., 2007. The economics of climate change and the change of climate in economics. Energy Policy 35, 5181-5194. doi:10.1016/j.enpol.2007.05.009

Marechal, K., Lazaric, N., 2010. Overcoming inertia: insights from evolutionary economics into improved energy and climate policies. Clim. Policy 10, 103-119. doi:10.3763/cpol.2008.0601

Margolis, S.E., 2009. Path Dependence and Public Policy: Lessons from Economics, in: Magnusson, L., Ottosson, J. (Eds.), The Evolution of Path Dependence. Edward Elgar, Cheltenham, UK, p. 240.

Mason, J., 2002. Qualitative Researching, second. ed. SAGE Publications Ltd, London.

Mazzucato, M., 2015. The Green Entrepreneurial State. SSRN Electron. J. doi: $10.2139 /$ ssrn.2744602

Navarro-Esbrí, J., Molés, F., Barragán-Cervera, Á., 2013. Experimental analysis of the internal heat exchanger influence on a vapour compression system performance working with R1234yf as a drop-in replacement for R134a. Appl. Therm. Eng. 59, 153-161. doi: 10.1016/j.applthermaleng.2013.05.028

Nekså, P., 2004. CO2 as refrigerant for systems in transcritical operation: principles and technology status, in: Forum.

Nishijima, D., 2016. Product lifetime, energy efficiency and climate change: A case study of air conditioners in Japan. J. Environ. Manage. 181, 582-589. doi:10.1016/j.jenvman.2016.07.010

North, D.C., 1990. Institutions, institutional change, and economic performance. Econ. Perspect. 5, 97-112.

O’Ryan, R., Ulloa, A., Asencio, G., 2006. Choosing policy instruments for controlling ozone depleting substances in a developing context: The case of Chile. J. Environ. Manage. 80, 347-362. doi:10.1016/j.jenvman.2005.09.021

Parkhurst, G., Parnaby, R., 2008. Growth in mobile air-conditioning: a socio-technical research agenda. Build. Res. Inf. 36, 351-362. doi:10.1080/09613210802076500

Perkins, R., 2003. Technological “lock-in .” Online Encycl. Ecol. Econ. 1-8.

Phan, T.N., Baird, K., 2015. The comprehensiveness of environmental management systems: The influence of institutional pressures and the impact on environmental performance. J. Environ. Manage. 160, 45-56. doi:10.1016/j.jenvman.2015.06.006

Seidel, S., Andersen, S.O., Hillbrand, A., 2016. Not-in-Kind Alternatives To High Global Warming Hfcs. Arlington, Virginia.

Shackley, S., Green, K., 2007. A conceptual framework for exploring transitions to decarbonised energy systems in the United Kingdom. Energy 32, 221-236. doi: 10.1016/j.energy.2006.04.010

Smit, M.F., van Heerden, P.D.R., Pienaar, J.J., Weissflog, L., Strasser, R.J., Krüger, G.H.J., 2009. Effect of trifluoroacetate, a persistent degradation product of fluorinated 
hydrocarbons, on Phaseolus vulgaris and Zea mays. Plant Physiol. Biochem. 47, 623-634. doi: $10.1016 /$ j.plaphy.2009.02.003

Spletzer, S., 2016. Tips for Surviving Refrigerant Transitions [WWW Document]. ACHR News. URL http://www.achrnews.com/articles/131667-tips-for-surviving-refrigeranttransitions-part--?v=preview (accessed 3.20.17).

UNEP, 2016. Montreal Protocol On Substances that Deplete the Ozone Layer: Report of the UNEP Technology and Economic Assessment Panel.

Unruh, G., 2000. Understanding carbon lock-in. Energy Policy 28, 817-830. doi:10.1016/S0301-4215(00)00070-7

Unruh, G.C., 2002. Escaping carbon lock-in. Energy Policy 30, 317-325. doi:10.1016/S03014215(01)00098-2

Valente, A.C., Domingues, A.R., Soares, C., Dias, G.P., Correa, I., Bossche, P. van den, Ramos, T.B., 2015. Green skills and innovation for inclusive growth, Green skills and innovation for inclusive growth. doi:10.2801/49143

van den Bergh, J.C.J.M., Faber, A., Idenburg, A.M., Oosterhuis, F.H., 2006. Survival of the greenest: evolutionary economics and policies for energy innovation. Environ. Sci. 3, 57 71. doi: $10.1080 / 15693430500481295$

Velders, G.J.M., Fahey, D.W., Daniel, J.S., McFarland, M., Andersen, S.O., 2009. The large contribution of projected HFC emissions to future climate forcing. Proc. Natl. Acad. Sci. U. S. A. 106, 10949-10954. doi:10.1073/pnas.0902817106

Virapongse, A., Brooks, S., Metcalf, E.C., Zedalis, M., Gosz, J., Kliskey, A., Alessa, L., 2016. A social-ecological systems approach for environmental management. J. Environ. Manage. 178, 1-9. doi:10.1016/j.jenvman.2016.02.028

Vollmer, M.K., Reimann, S., Hill, M., Brunner, D., 2015. First observations of the fourth generation synthetic halocarbons HFC-1234yf, HFC-1234ze(E), and HCFC-1233zd(E) in the atmosphere. Environ. Sci. Technol. 49, 2703-2708. doi:10.1021/es505123x

Walker, W., 2000. Entrapment in large technology systems: institutional commitment and power relations. Res. Policy 29, 833-846. doi:10.1016/S0048-7333(00)00108-6

Wilhite, H., 2009. The conditioning of comfort. Build. Res. Inf. 37, 84-88. doi: $10.1080 / 09613210802559943$

Wodzisz, R., 2015. Case Study of R-1234yf Refrigerant: Implications for the Framework for Responsible Innovation. Sci. Eng. Ethics 21, 1413-1433. doi:10.1007/s11948-014-9612-2

Woerdman, E., 2015. The institutional economics of market-based climate policy, The effects of brief mindfulness intervention on acute pain experience: An examination of individual difference. doi:10.1017/CBO9781107415324.004 